\title{
Molecular cloning and sequence analysis of stearoyl-CoA desaturase in milkfish, Chanos chanos
}

\author{
S.L. Hsieh ${ }^{\mathrm{a}}$, W.L. Liao ${ }^{\mathrm{a}}$, C.M. Kuo ${ }^{\mathrm{b}, *}$ \\ a Institute of Fisheries Science, National Taiwan University, Taipei 106, Taiwan, ROC \\ ${ }^{\mathrm{b}}$ Department of Aquaculture, National Pingtung University of Science and Technology, Pingtung 912, Taiwan, ROC
}

Received 25 April 2001; received in revised form 15 July 2001; accepted 19 July 2001

\begin{abstract}
Stearoyl-CoA desaturase (EC 1.14.99.5) is a key enzyme in the biosynthesis of polyunsaturated fatty acids and the maintenance of the homeoviscous fluidity of biological membranes. The stearoyl-CoA desaturase cDNA in milkfish (Chanos chanos) was cloned by RT-PCR and RACE, and it was compared with the stearoyl-CoA desaturase in cold-tolerant teleosts, common carp and grass carp. Nucleotide sequence analysis revealed that the cDNA clone has a 972-bp open reading frame encoding 323 amino acid residues. Alignments of the deduced amino acid sequence showed that the milkfish stearoyl-CoA desaturase shares $79 \%$ and $75 \%$ identity with common carp and grass carp, and $63 \%-64 \%$ with other vertebrates such as sheep, hamsters, rats, mice, and humans. Like common carp and grass carp, the deduced amino acid sequence in milkfish well conserves three histidine cluster motifs (one HXXXXH and two HXXHH) that are essential for catalysis of stearoyl-CoA desaturase activity. However, RT-PCR analysis showed that stearoyl-CoA desaturase expression in milkfish is detected in the tissues of liver, muscle, kidney, brain, and gill, and more expression sites were found in milkfish than in common carp and grass carp. Phylogenic relationships among the deduced stearoyl-CoA desaturase amino acid sequence in milkfish and those in other vertebrates showed that the milkfish stearoyl-CoA desaturase amino acid sequence is phylogenetically closer to those of common carp and grass carp than to other higher vertebrates. (c) 2001 Elsevier Science Inc. All rights reserved.
\end{abstract}

Keywords: Stearoyl-CoA desaturase; cDNA; Milkfish; Rapid amplification of cDNA ends (RACE); Expression; Polymerase chain reaction (PCR); Histidine motifs; Phylogenetic relationship

\section{Introduction}

Fatty acid desaturases play important roles in the physiological functioning of cell membranes and in fatty acid metabolism (Jeffcoat, 1979; Tiku et al., 1996). To date, three types of desaturases have been recorded: Acyl-CoA, Acyl-lipid, and Acyl-ACP desaturases (reviewed in Los and $\mathrm{Mu}$ -

\footnotetext{
* Corresponding author. Tel.: +886-8-7703202 ext. 6373; fax: + 886-8-7740344.

E-mail address: cmkuo@mail.npust.edu.tw (C.M. Kuo).
}

rata, 1998). Acyl-CoA desaturases are the enzymes involved in the CoA-bound desaturation of fatty acids in animals and yeasts (Thiede et al., 1986; Luo et al., 1997). In plants and cyanobacteria, acyl-lipid desaturases introduce double bonds into the fatty acids, which are bound to glycerolipids (Sperling et al., 1990). In addition, higher plants contain acyl-ACP desaturase, which catalyzes desaturation reactions when fatty acids are bound to the acyl carrier protein (ACP) (Thompson et al., 1991).

Stearoyl-CoA desaturase (EC 1.14.99.5), one of 
the acyl-CoA desaturases representing the first regulatory step in the formation of long-chain unsaturated fatty acids (Enoch et al., 1976), is responsible for introduction of the first double bond between carbons 9 and 10 of palmitoyl (16:0)- and stearoyl (18:0)-CoA to form the mono-unsaturated palmitoleic (16:1) and oleic acids (18:1), respectively (Jeffcoat et al., 1977). These desaturation processes are also catalyzed by microsomal enzyme systems: cytochrome $b_{5}$, $\mathrm{NADH}$-dependent cytochrome $b_{5}$ reductase and stearoyl-CoA desaturase (Holloway, 1971; Rogers and Strittmatter, 1973; Strittmatter et al., 1974). Cytochrome $b_{5}$ can transfer electrons from its internal heme to the iron centers of the stearoylCoA desaturase (Itoh et al., 1998).

In thermal acclimation, there are speciesspecific differences in the types of desaturase that contribute to lipid restructuring. For examples, $\Delta^{9}$ desaturase plays an important role in the lipid composition for carp in the cold (Macartney et al., 1996; Tiku et al., 1996), and $\Delta^{12}$ plays a more significant role in thermal acclimation than $\Delta^{6}$ and $\omega 3$ desaturases for $E$. coli (Panpoom et al., 1998). Living organisms, poikilotherms in particular, respond to a downward shift in temperature by desaturating the fatty acids of their membrane lipids, which exert modulative effects upon the actions of membrane-bound enzymes. This homeoviscous acclimation response reflects the ability to maintain the fluidity of biological membrane over a certain range of temperatures. The ability of cells to modulate the physical characteristics of the membrane lipids is mainly determined by the action of desaturase, which introduces double bonds into fatty acids (Lee and Cossins, 1990; Murata and Wada, 1995). Since more than 30 species of fatty acids may be combined in different pairings on the membrane phospholipids, the compositional differences between cold- and warm-acclimated animals are extremely complex. However, the most common pattern is that cold acclimation leads to an increased proportion of fatty acids containing unsaturated bonds at the expense of saturated homologues (Cossins and Bowler, 1987).

Although stearoyl-CoA desaturase is not the only desaturase involved in modulating membrane lipid restructuring, it has also been recognized as one of the important desaturases involved in the processes of acclimation to stressful environments, including lipid metabolism, obesity, cell-membrane fluidity and signal transduction (Legrand and Hermier, 1992; de Antueno et al., 1993; Györfy et al., 1997). Among these, the maintenance of cell membrane fluidity through changes in the fatty acid composition of the membrane is achieved by the action of stearoyl-CoA desaturase, which therefore plays a significant role in the thermal adaptation of fish in fluctuating environmental conditions (Nakashima et al., 1996).

Stearoyl-CoA desaturase has been isolated from a variety of vertebrates. These include Long Evans rats (Thiede et al., 1986); mice, Mus musculus (Ntambi et al., 1988; Kaestner et al., 1989); hamsters, Mesocricetus auratus (Ideta et al., 1995); common carp, Cyprinus carpio (Tiku et al., 1996); sheep, Ovis aries (Ward et al., 1998); humans, Homo sapiens (Zhang et al., 1999); and grass carp, Ctenopharyngodon idella (Chang et al., 2001).

Milkfish, widely distributed in tropical and subtropical waters, have traditionally been considered a commercially important cultured warm-water species in the Southeast Asian region (Bagarinao, 1994). Heavy mortality by winter kill of this species has often been reported. Since stearoyl-CoA desaturase has only been reported in cold-tolerant teleosts, common carp and grass carp to date, the objectives of this research were to confirm the presence of stearoyl-CoA desaturase in milkfish, and furthermore to pursue the cloning and sequencing of the cDNA encoding the milkfish stearoyl-CoA desaturase by RT-PCR and RACE methods and gene expression in this species.

\section{Materials and methods}

\subsection{Animals}

Milkfish (Chanos chanos) were collected from the Tainan Station of the Taiwan Fisheries Research Institute. Upon arrival in our laboratory, they were acclimated in freshwater at $25^{\circ} \mathrm{C}$ and a $12 \mathrm{~L} / 12 \mathrm{D}$ photoperiod regime, and fed with commercially formulated feed. The average weight was $140.03 \pm 8.74 \mathrm{~g}$.

\section{2. $R N A$ isolation}

Total RNA was isolated following the method described by Chomczynski and Sacchi (1989). 
Liver was homogenized in a guanidine solution (5 $\mathrm{M}$ guanidinium thiocyanate, $50 \mathrm{mM}$ Tris, $\mathrm{pH} 7.5$, $10 \mathrm{mM}$ EDTA, 8\% $\beta$-mercaptoethanol and 2\% sarcosyl). The homogenate was centrifuged at $15000 \times g$ for $30 \mathrm{~min}$. The supernatant was applied onto a $5.7 \mathrm{M} \mathrm{CsCl}$ cushion and ultracentrifuged at $35000 \times g$ for $16 \mathrm{~h}$. The RNA pellet was dissolved in DEPC-treated water and extracted twice with phenol/chloroform $(1: 1, \mathrm{v} / \mathrm{v})$, followed by chloroform extraction. Total RNA was precipitated in $75 \%$ ethanol containing sodium acetate, and was then washed with $75 \%$ ethanol. The RNA pellet was dissolved in a small amount of DEPC-treated water, and its concentration was adjusted to $1 \mu \mathrm{g} / \mu \mathrm{l}$. Samples were stored at $-80^{\circ} \mathrm{C}$ until use.

\subsection{Molecular cloning}

Full-length cDNA was obtained by the procedures of reverse transcription polymerase chain reaction (RT-PCR) and rapid amplification of cDNA ends (RACE). For RT-PCR, first-strand DNA was synthesized by MMLV reverse transcriptase (Life Sciences) using poly $(\mathrm{A})^{+}$RNA with oligo(dT) as the primer. The reverse transcripts were used as a template for the following PCR with two degenerate primers. The forward primer was $5^{\prime}-\mathrm{A}(\mathrm{A} / \mathrm{G}) \mathrm{AA}(\mathrm{T} / \mathrm{C}) \mathrm{G} \mathrm{A}(\mathrm{T} / \mathrm{C}) \mathrm{A} \mathrm{T}$ (T/C/A)TA(T/C)GA(A/G)TGG-3', and the reverse primer was $5^{\prime}-\mathrm{GT}(\mathrm{A} / \mathrm{G}) \mathrm{TG}(\mathrm{A} / \mathrm{G})$ TG(A/G)TA(A/G)TT(A/G)TG(A/G)AA-3', corresponding to amino acid sequences QNDIYEW and FHNYHHT, respectively. PCR was performed with the two primers under the following conditions: 25 cycles of $94^{\circ} \mathrm{C}$ for $1 \mathrm{~min}$, $45^{\circ} \mathrm{C}$ for $1 \mathrm{~min}$, and then $72^{\circ} \mathrm{C}$ for $2 \mathrm{~min}$. The last step was extended for $10 \mathrm{~min}$ at $72^{\circ} \mathrm{C}$. The PCR product was electrophoresed in $1 \%(\mathrm{w} / \mathrm{v})$ agarose gel. Every $50-\mu 1$ PCR reaction contained approximately $1 \mu \mathrm{g}$ total RNA as the template, $200 \mu \mathrm{M}$ dNTPs (dATP, dCTP, dGTP and dTTP), $200 \mathrm{nM}$ of the desaturase primer set, $1 \times$ PCR buffer (containing $1.5 \mathrm{mM} \mathrm{MgCl} 2$ ), and 2.5 units of Taq DNA polymerase.

For 5'-RACE, $3 \mu \mathrm{g}$ of total RNA was reversetranscribed with the first nested P1 primer, which is specific to the milkfish desaturase gene. The first-strand cDNA used for $5^{\prime}$-RACE was performed as above, then tailed at the $5^{\prime}$-end by terminal transferase TdT (Boehringer Mannheim) and dGTP. The primer sets consisted of P1 and
Table 1

Nucleotide sequence of the primers in milkfish

\begin{tabular}{llr}
\hline Name & Nucleotide sequence $\left(5^{\prime}-3^{\prime}\right)$ & $\begin{array}{l}\text { cDNA } \\
\text { position }\end{array}$ \\
\hline N1 & ARAAY GAYAT HTAYG ARTGG & $332-351$ \\
C2 & GTRTG RTGRT ARTTR TGRAA & $790-781$ \\
MD1 & ACACT TTCCT TGGAC AAATT GTGTG & $88-100$ \\
MD2 & AGCCA GGTCG CGTTA AGGAC & $680-661$ \\
MFQ1 & GTCCT TAACG CGACC TGGCT & $661-680$ \\
MFQ2 & TGTGG GGCAT GAGGC CCTAC & $701-720$ \\
MFP1 & ACCAG CAGCC AGCCG ACGTG & $452-433$ \\
MFP2 & CTTGT GGTGA ACACG ATGGT & $377-358$ \\
\hline
\end{tabular}

The symbols used to donate multiple nucleotides are as follows: $\mathrm{R}=\mathrm{A}+\mathrm{G} ; \mathrm{Y}=\mathrm{C}+\mathrm{T} ; \mathrm{M}=\mathrm{A}+\mathrm{C} ; \mathrm{K}=\mathrm{G}+\mathrm{T} ; \mathrm{W}=$ $\mathrm{A}+\mathrm{T} ; \mathrm{H}=\mathrm{A}+\mathrm{C}+\mathrm{T} ; \mathrm{B}=\mathrm{C}+\mathrm{G}+\mathrm{T} ; \mathrm{V}=\mathrm{A}+\mathrm{C}+\mathrm{G} ; \mathrm{D}=$ $\mathrm{A}+\mathrm{G}+\mathrm{T} ;$ and $\mathrm{N}=\mathrm{A}+\mathrm{T}+\mathrm{C}+\mathrm{G}$.

the anchor primer, PT1, for the first-run PCR, and P2 and PT2 for the second-run PCR (Table 1). The PCR conditions described above were followed for RT-PCR, except that the annealing temperature was elevated to $50^{\circ} \mathrm{C}$. The procedure for 5'-RACE was also applied to that for $3^{\prime}$ RACE. Total RNA was reverse-transcribed after annealing with anchor primer PT1. Two successive PCRs were performed with the primer sets Q1 and PT2 for the first run and Q2 and PT2 for the second run (Table 1). Amplification products were fractionated on $1 \%$ agarose gels, from which selected DNA bands were purified. They were ligated directly into the vector of PGEM-T Easy (Promega), and the plasmids were used to transform them into Escherichia coli XL1 blue cells. Plasmid DNA was purified for sequencing by the QIAperp miniperp kit (Qiagen). Positive clones were further confirmed according to the presence of the expected amino acid sequence.

\subsection{Tissue expression analysis}

Tissue expression of stearoyl-CoA desaturase mRNA was demonstrated by RT-PCR. Total RNA at $10 \mu \mathrm{g}$ from various tissues (liver, muscle, kidney, brain, heart, and gill) was reverse-transcribed with oligo(dT). Two primers (MD1 and MD2) specific to milkfish desaturase were used (Table 1). The reaction conditions included an initial step at $94^{\circ} \mathrm{C}$ for $2 \mathrm{~min}$, followed by 30 cycles at $94^{\circ} \mathrm{C}$ for $1 \mathrm{~min}, 55^{\circ} \mathrm{C}$ for $1 \mathrm{~min}$, and $72^{\circ} \mathrm{C}$ for 2 min. A final extension step was performed at $72^{\circ} \mathrm{C}$ for $6 \mathrm{~min}$. The PCR reaction without the cDNA template was performed simultaneously. 


\subsection{Nucleotide DNA sequencing}

The nucleotide sequence of the cDNA was determined with a dye terminator-cycle sequencing kit (Perkin-Elmer, Applied Biosystems) on a model 373A DNA sequencer (Perkin Elmer, Applied Biosystems). Clones were the sequence M13 forward and reverse primers.

\subsection{Sequence analysis}

The BLAST sequence analysis program (http:/ www.ncbi.nlm.nih.gov/BLAST/) was used for initial sequence comparisons. Multiple alignment of stearoyl-CoA desaturase from human (Homo sapiens, GenBank accession no. AF097514), rat (Long Evans, GenBank accession no. J02585), mouse (Mus musculus, GenBank accession no. NM009127), sheep (Ovis aries, GenBank accession no. AJ001048), hamster (Mesocricetus auratus, GenBank accession no. L26956), carp (Cyprinus carpio, GenBank accession no. U31864) and grass carp (Ctenopharyngodon idella, GenBank accession no. AJ243835) was performed with CLUSTAL W, a Windows interface for the CLUSTAL W multiple sequence alignment program (Thompson et al., 1994). PHYLIP, the Phylogeny Inference Package (version 3.57C) (Felsenstein, 1995) was used to construct the phylogenetic trees. Distances were calculated with 'protdist' of the PAM-Dayhoff matrix, and the trees were constructed using the neighbor-joining method after 1000 bootstrap replicates using programs from the PHYLIP 3.57 package.

\section{Results}

\subsection{Cloning of $c D N A$ encoding stearoyl-CoA desaturase}

Two degenerate oligonucleotide primers, N1 and $\mathrm{C} 1$, were designed following the sequence characteristics of stearoyl-CoA desaturase presented in Table 1. Using these primers, PCR was carried out with single-stranded cDNA synthesized with $\operatorname{poly}(\mathrm{A})^{+}$RNA from milkfish liver as a template. A major product of $468 \mathrm{bp}$ was compared with stearoyl-CoA desaturases reported elsewhere. The cDNA sequence of this fragment has a high identity to common carp $(81 \%)$, grass carp $(82 \%)$ and rat $(85 \%)$ stearoyl-CoA desat- urases. According to this sequence information, four specific primers were designed, and the 3 'and $5^{\prime}$-ends of the cDNA were obtained using a RACE protocol (Table 1). The nucleotide and deduced amino acid sequences of DNA encoding the putative desaturase of milkfish stearoyl-CoA desaturase are presented in Fig. 1. Using similar approaches, $323 \mathrm{bp}$ of the cDNA fragment was amplified by $5^{\prime}$-RACE, and 135 bp of the $3^{\prime}$-end cDNA was obtained by $3^{\prime}$-RACE. The full-length cDNA comprises $1073 \mathrm{bp}$, including $36 \mathrm{bp}$ in the $5^{\prime}$-untranslated region, 972 bp in the open reading frame (ORF) that encodes 323 amino acid residues, and $65 \mathrm{bp}$ in the $3^{\prime}$-translated region.

\subsection{Comparison of amino acid sequences}

The amino acid sequences from eight different vertebrates are compared in Fig. 2. The milkfish stearoyl-CoA desaturase amino acid sequence shows relatively high identity and similarities to deduced desaturase amino acid sequences of other vertebrates: 79 and $87 \%$ to common carp; 75 and $84 \%$ to grass carp; 64 and $79 \%$ to rat; 64 and $80 \%$ to human; 63 and $79 \%$ to sheep; 63 and $79 \%$ to hamster; and 64 and $80 \%$ to mouse, respectively. Like most desaturases in other vertebrates, three histidine clusters are well conserved in the sequence in milkfish. One HXXXXH (residues 84-89) and two HXXHH (residues 121-125 and 262-266), as underlined in Fig. 2, are essential for catalysis of stearoyl-CoA desaturase activity (Shanklin et al., 1994). On the contrary, the Nterminal sequences are highly variable between fish and other vertebrates, indicating that this region is probably not as relevant to enzymatic functions. Hydropathy profiles of the deduced amino acid sequence analysis are presented in Fig. 3. Two hydrophobic regions of milkfish stearoyl-CoA desaturase are conserved the same as in vertebrate rat, common carp and grass carp stearoyl-CoA desaturase.

\subsection{Polymorphism}

In order to clarify the molecular evolutionary relationship between milkfish stearoyl-CoA desaturase and those of other vertebrates, a phylogenetic tree produced by the CLUSTAL $\mathrm{W}$ program was attempted (Thompson et al., 1994) (Fig. 4). The milkfish stearoyl-CoA desaturase sequence is phylogenetically closer to those of teleosts, com- 


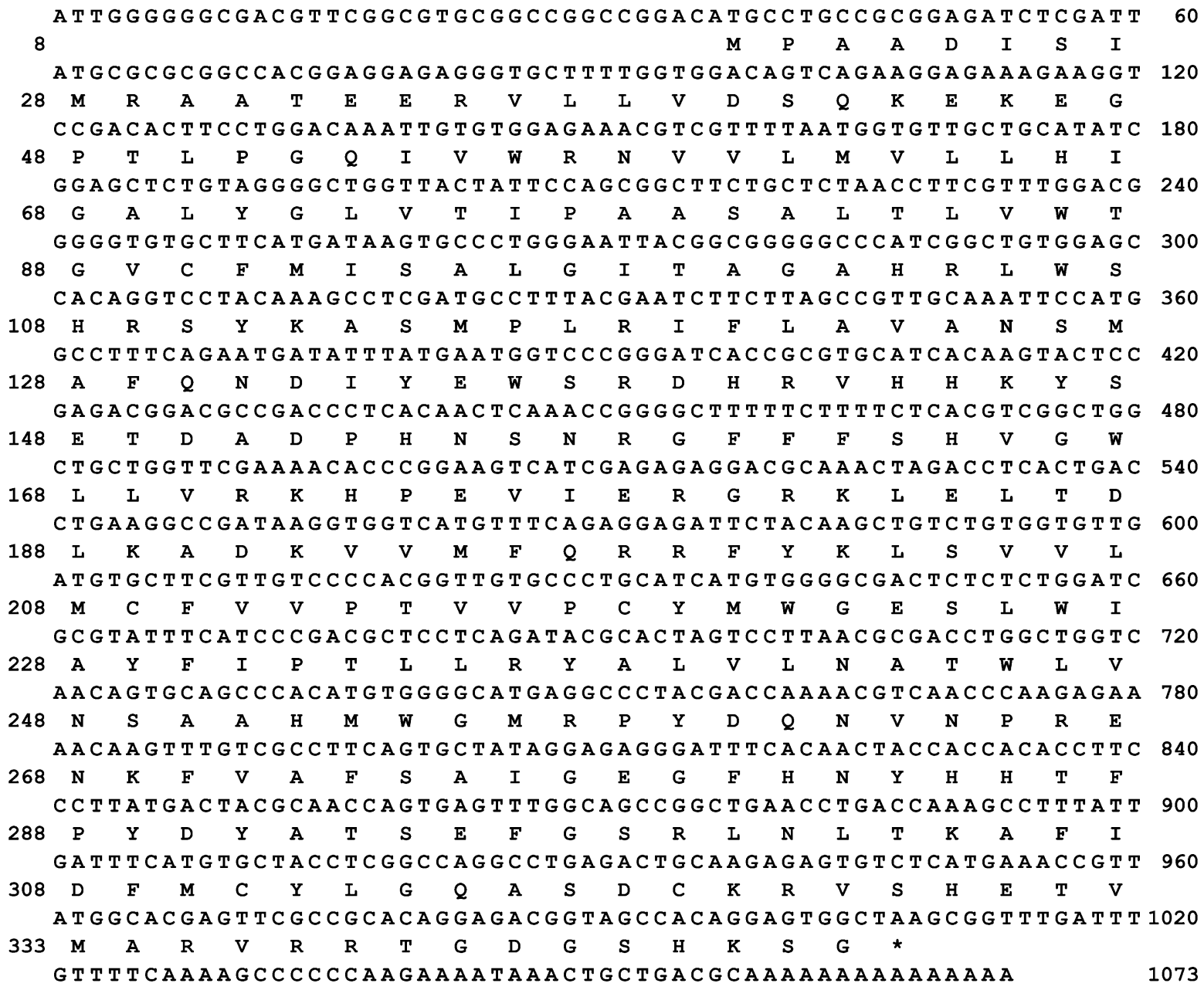

Fig. 1. Nucleotide and deduced amino acid sequences of milkfish desaturase. The amino acid sequence is shown below the nucleotide sequence in a single letter code. The translation start codon and termination codon are marked by an $\mathrm{M}$ and asterisk $(*)$, respectively. The polyadenylation signal is underlined.

mon carp and grass carp, than to those of different phyla.

\subsection{Tissue expression}

Tissue expression of stearoyl-CoA desaturase in various tissues of milkfish is shown in Fig. 5. Expression of stearoyl-CoA desaturase mRNA was demonstrated by RT-PCR. In a RT-PCR study, a 592-bp fragment was amplified with the stearoyl-CoA desaturase-specific primers (MD1 and MD2, Table 1) that were derived from the cDNA of all tissues examined, i.e. the liver, brain, kidney, gill and muscle. However, the desaturase was strongly detected only in liver and brain for grass carp (Chang et al., 2001).

\section{Discussion}

Full-length stearoyl-CoA desaturase cDNA from milkfish (Chanos chanos) was successfully cloned using an RT-PCR strategy. Since the temperature tolerance and adaptation mechanisms for fish in different temperature niches differ, variabilities in the subcellular desaturase expression and activity, which are intimately related to thermal adaptation, are expected (Schünke and Wodtke, 1983). In searching for stearoyl-CoA desaturase in milkfish, a 1073-bp cDNA encoding a protein sequence of 323 amino acids by reversetranscription polymerase chain reaction (RTPCR) and rapid amplification of cDNA ends (RACE) was obtained. The deduced amino acid 


\begin{tabular}{|c|c|c|}
\hline MILKFISH & $--\overline{V D}-\mathbf{S Q}$ & 23 \\
\hline GRASSOCARP & $---D H T Y$ & 24 \\
\hline CARP & $---D H T Y$ & 26 \\
\hline HAMSTER & DIRPEMKEDIYDPSY & 54 \\
\hline SHEEP & MPÄHLLQEEISSSYTTTTT- & 59 \\
\hline MOUSE & MPAHMLQ-EISSSYTTTTTI & 55 \\
\hline RAT & MPAHMIQ-EISSSYTTTTTI & 58 \\
\hline HUMAN & MPAHLLQDDISSSYTTTTTI & 59 \\
\hline MILKFISH & ALGITAGA & 83 \\
\hline GRASS CARP & ALGITAGA & 84 \\
\hline CARP & FFGCLIESALGITAGA & 86 \\
\hline HAMSTER & AFVYYVISIEGIGAGV & 114 \\
\hline SHEEP & DKEGPK్̈PKLEYVWRNI ILMEL. & 119 \\
\hline MOUSE & SALGITAGA & 115 \\
\hline RAT & QDFEGPPPKLEYVWRNIILMALLHVGALYGITLIPSSKV & 118 \\
\hline HUMAN & KDKEGPSPKVEYVWNIILMSLLHLGALYGITLIPTCKFY & 119 \\
\hline MILKFISH & HKYYSETDADPHNSNIRGFFF & 143 \\
\hline GRASS CARP & IKYSETDADPHNAVRGFFF & 144 \\
\hline CARP & RLWSHRSYKASLPLQI FLALGNSMAFQNDIYEWSRDHRVHHKYSETDADPHNAVRGFFF & 146 \\
\hline HAMSTER & RLWSHRYKARLPLRIFLIIANTMAFQNDVYEWARDHRAHHKFSETYADPHDSRGFFF & 174 \\
\hline SHEEP & ZLWSHRTYKARLPLRV్VFLIIANTMAFQNDVFEWSRDHRAHHKFSETDADPHNSRRGFFF & 179 \\
\hline MOUSE & RLWSHRTYKARLPLRIFLI IANTMAFQNDVYDWARDHRAHHKFSETHADPHNSRRGFFF & 175 \\
\hline RAT & RLWSHRTYKARLPLRIFLI IANTMAFQNDVYEWARDHRAHHKFSETHADPHNSRRGFFF & 178 \\
\hline HUMAN & RLWSHRSYKARLPLRIFLIIANTMAFQNDVYEWARDHRAHHKFSETHADPHNSRRGFFF & 179 \\
\hline MILKFISH & KLFLTDLKADKVVMFQRRFYKLSVVLMCFVV & 203 \\
\hline GRASS CARP & IVRKHPDVIEKGRKLEISDLKADKVVMFQRRHYKPSVLLMCFEVPMEVPWFEWG & 204 \\
\hline CARP & SHVGWLLVRKHPDVIEKGRKLELSDLKADKVVMFQRRFYKPSVLLMCFFVPTFPWYVWG & 206 \\
\hline HAMSTER & ELVRKHPAVKEKGGKLDMSDLKAEKLVMFQRRYYKPAILLMCFILPTFVPWYFWG & 234 \\
\hline SHEEP & SHVGWLLVRKHPAVREKGATLDLSDLRAEKLVMFQRRYYKPGVLLLCFILPTLVPWYLWG & 239 \\
\hline MOUSE & SHVGWLLVRKHPAVKEKGGKLDMSDLKAEKLVMFQRRYYKPGLLLMCFILPTLVPWYCWG & 235 \\
\hline RAT & DMSDLKAEKLVMFQRRYYKPGLLIMCFILPTLVPWYCWG & 238 \\
\hline HUMAN & SHVGWLLVRKHPAVKEKGSTLDISDLEAEKLVMFQRRYYKPGLLMMCFILPTLVPWYEWG & 239 \\
\hline MILKFISH & VNSAAHMẄGMRPYDQN & 263 \\
\hline GRASS CARP & RENREVTFSAIGEGFHN & 264 \\
\hline CARP & VNSAAHMWGNRPYDSSINPRENREVTFSAIGEGFHN & 266 \\
\hline HAMSTER & TWLVNSAAHLYGYRPYDKNIDPRENALLVSLGCLGEGFHN & 294 \\
\hline SHEEP & IATWLVNSAAHMYGYRPYDKTINPRENILVSLGAVGEGFHN & 299 \\
\hline MOUSE & VSTFLRYTLVLNATWLVNSAAHLYGYRPYDKNIQSRENILVSLGAVGEGFHN & 295 \\
\hline RAT & VSTFLRYTLVLNATWLVNSAAHLYGYRPYDKNIQSRENILVSLGSVGEGFHN & 298 \\
\hline HUMAN & VAAPTLRYAVVLNATWLVNSAAHLEGYRPYDKNISPRENILVSLGAVGEGFHN & 299 \\
\hline MILKFISH & YLGQASDCKRVSHETVMARVRRTGDGSHKSG & 323 \\
\hline GRASS CARP & FDYSTSEYGWTKLNLTC-FIDLMCFLGLASDPKRVSREAVIARVQRTGDGSHRSG & 324 \\
\hline CARP & YHHTFPEDYATSEFGCKLNLTTCCFIDLMCELGLAREAKRVSREAVLARARRTGDGSHWWSG & 327 \\
\hline HAMSTER & YHHAFPYDYSASEYRWHINFTT-FFIDCMĀLGLAYDRKKVSKAAVLARIKRTGDGSCKSG & 354 \\
\hline SHEEP & YHHTFPYDYSASEYRWHINFTT-FFIDCMAAIGLAYDRKKVSKAAVLGRMKRTGDGNIYKSG & 359 \\
\hline MOUSE & YHHTFPEDYSASEYRWHINFTTF-FIDCMAALGLAYDRKKVSKATVLARIKRTGDGSHKSS & 355 \\
\hline RAT & YHHAFPȲDYSASEYRWHINFTTF-FIDCMAALGLAYDRKKVSKAĀVLARIKRTGDGSHKSS & 358 \\
\hline HUMAN & 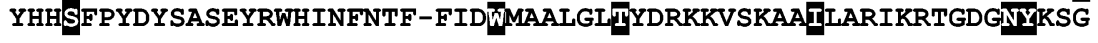 & 359 \\
\hline
\end{tabular}

Fig. 2. Multiple alignments of stearoyl-CoA desaturases. Different amino acid residues among species are presented on a black background. Three conserved histidine clusters (one of HXXXXH and two of HXXHH) are underlined. Deduced amino acid sequences were obtained from human desaturase (GenBank/EMBL accession no. AF097514), mouse (NM009127), rat (J02585), sheep (AJ001048), hamster (L26956), carp (U31864), and grass carp (AJ243835).

sequence of stearoyl-CoA desaturase in milkfish shares high homology with those of other coldtolerant teleosts, $79 \%$ to common carp, and $75 \%$ to grass carp. Fairly high identities to mammalian desaturase in the range $63-64 \%$ were also demonstrated. The phylogenetic analysis suggests 

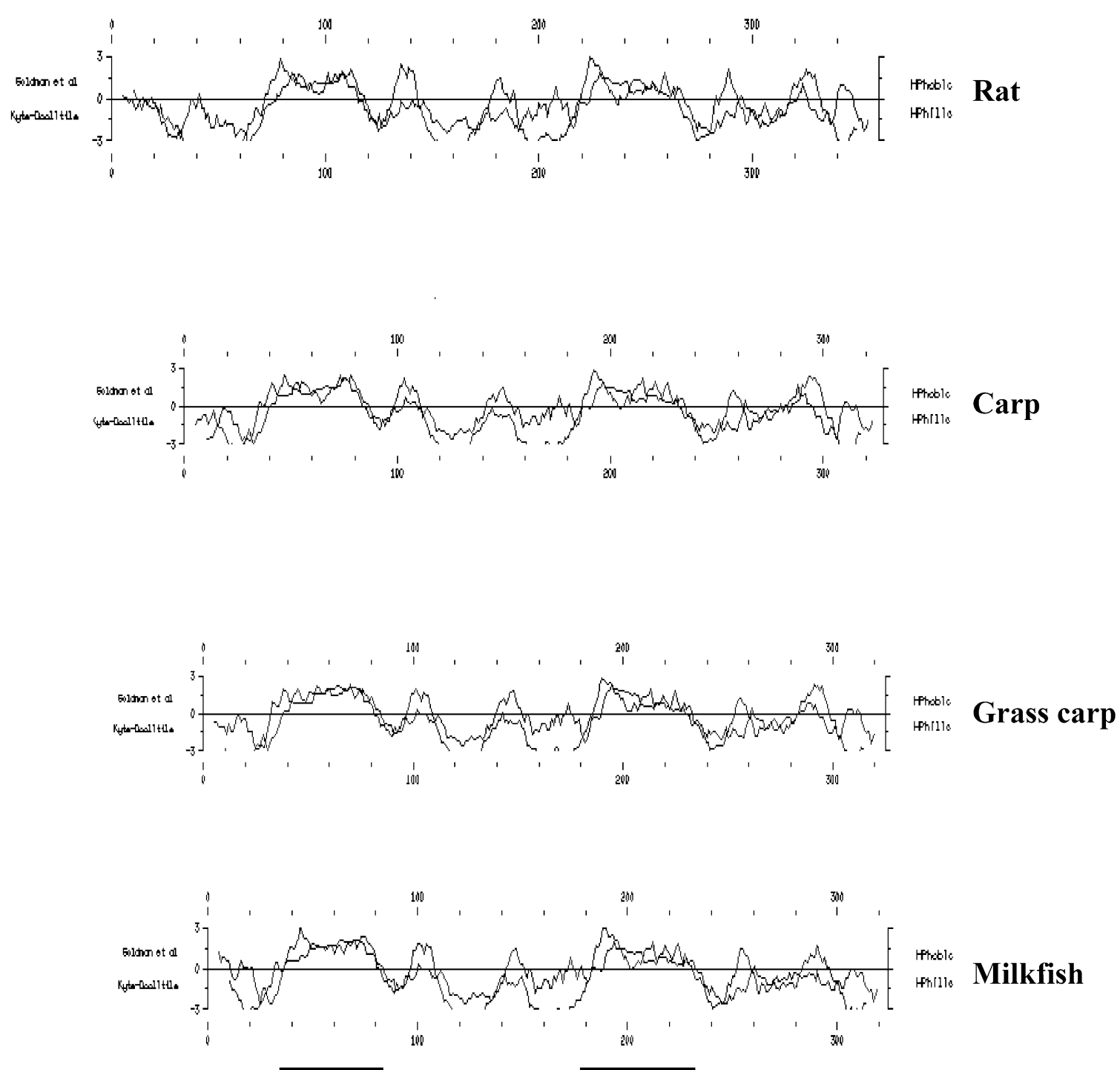

Fig. 3. Kyto-Doolittle hydropathy analysis of rat, carp, grass carp, and milkfish stearoyl-CoA desaturase (Kyto and Doolittle, 1982). The presumptive double membrane-spanning regions are underlined.

that milkfish desaturase is closely related to those of other vertebrates, with $100 \%$ bootstrap value to common carp and grass carp. The stearoyl-CoA desaturase sequence in milkfish contained three histidine cluster motifs: one HXXXXH and two $\mathrm{HXXHH}$, which are all conserved in the stearoylCoA desaturases of vertebrates reported to date. The role of these histidine residues is likely to act as ligands to iron atoms that are involved in electron transfer, and thus oxidation-redaction reactions for the insertion of double bonds into fatty acids (Strittmatter et al., 1974).

By hydropathy analysis, two long hydrophobic regions were found to be conserved in milkfish
stearoyl-CoA desaturase. These regions potentially exist in two membrane-spanning domains that are characteristic of membrane-anchored proteins and generally found in both acyl-CoA and acyl-lipid desaturases (Stukey et al., 1990; Murata and Wada, 1995). This speculation is consistent with the finding that stearoyl-CoA desaturase is tightly bound to microsome membranes.

Influences on desaturase activities and expression have been the subject of controversy. Factors, including nutrient conditions (Ntambi, 1992; Tocher et al., 1996), hormones (Miller et al., 1997; Waters et al., 1997), peroxisomal proliferation (Miller and Ntambi, 1996), developmental 


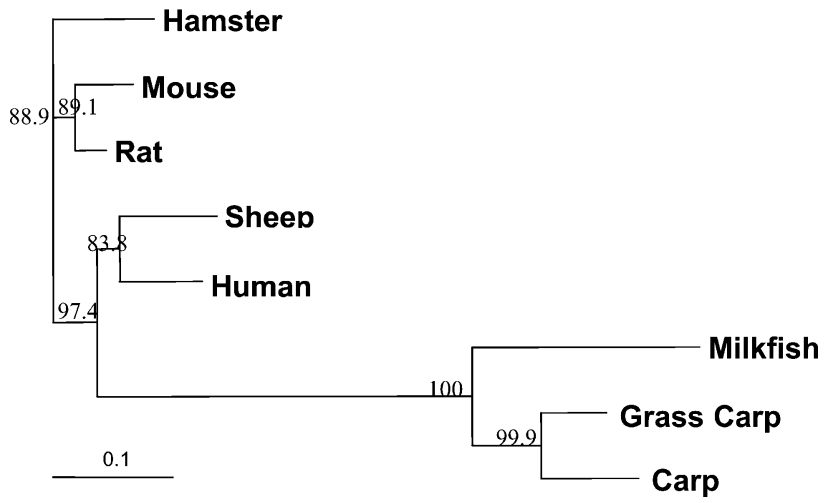

Fig. 4. Phylogenetic tree of eight vertebrate stearoyl-CoA desaturase sequences. A multiple alignment of amino acid sequences was performed using CLUSTAL W (Thompson et al., 1994). PHYLIP (Phylogeny Inference Package) version 3.57c (Felsenstein, 1995) was used to construct phylogenetic trees. Bootstrap values are indicated at the nodes. The scale bar indicates distance in units of fraction of amino acid differing between two sequences.

processes (Casimir and Ntambi, 1996), and environment conditions such as temperature (Tiku et al., 1996), have been investigated in various species. In starved rainbow trout, refeeding produced significant effects on the induction of stearoyl-CoA desaturase expression and activity within 1 week (Tocher et al., 1996). Furthermore, desaturase was notably expressed by cold shock in common carp, and the transcription of stearoylCoA desaturase in hepatic tissue increased 40-50-fold (Trueman et al., 2000). Similarly, transcription of stearoyl-CoA desaturase in milkfish liver also increased under cold shock (data not shown).

Although the molecular structure of desaturase is well conserved among various vertebrates, the expression pattern of desaturase appears to differ among them, and species-specific variations exist. Two types of desaturase genes were found in rodents: SCD-1 and SCD-2. SCD1 and SCD2 are different isoforms of stearoyl-CoA desaturase enzyme. Nucleotide sequence analysis of SCD1 and SCD2 genes revealed that the six exons and five introns span approximately $15 \mathrm{~kb}$. Unlike the SCD1 gene, SCD2 lacks a typical 'TATA' box in the 5'-flanking region, but has two 'CCAAT' boxes at the transcription site (Kaestner et al., 1989). SCD-1 is principally expressed in adipose tissue and mildly expressed in the lung, while SCD-2 is predominantly expressed in the brain and less abundantly in the lung, spleen, and kidney (Ntambi et al., 1988; Kaestner et al., 1989; Mihara, 1990). In sheep, a single desaturase mRNA is highly expressed in the liver and mammary gland, whereas a low level of expression is detectable in the brain, muscle, lung, kidney, heart, and adipose tissue (Ward et al., 1998). As for human desaturase, two alternative transcripts are generated from a single gene, and its transcripts are abundant in the brain and liver, and also detectable in the lung, heart, placenta, skeletal, muscle, and kidney (Zhang et al., 1999). Among teleosts, the expression of the stearoylCoA desaturase in milkfish is tissue-specific, and

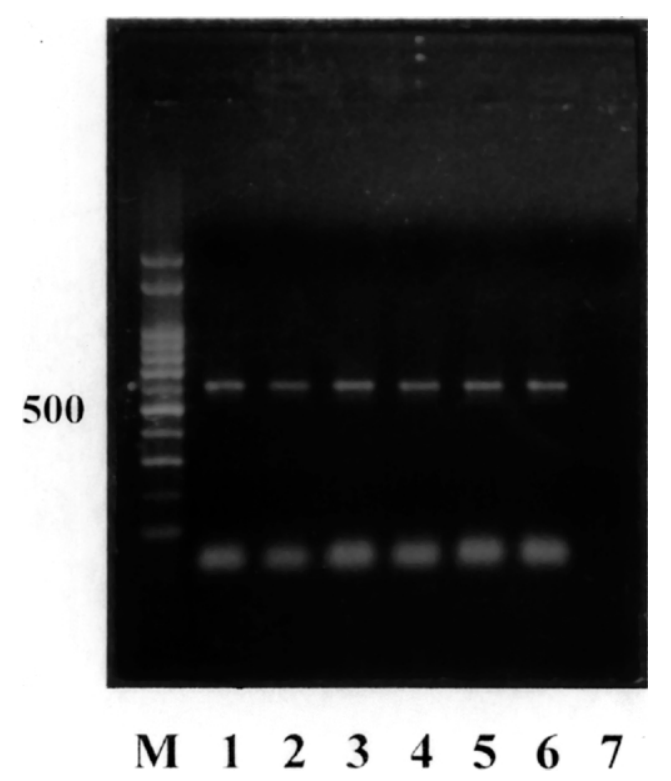

Fig. 5. RT-PCR analysis of stearoyl-CoA desaturase expression in various tissue. Tissues are indicated as follows: lane $\mathrm{M}$, DNA marker; lane 1, liver; lane 2, brain; lane 3, kidney; lane 4 , gill; lane 5, heart; and lane 6 , muscle. The expression of stearoyl-CoA desaturase was also analyzed by RT-PCR with primers specific to milkfish stearoyl-CoA desaturase. The PCR products were analyzed on $1.2 \%$ gels. 
transcripts of the gene are expressed in liver, brain, kidney, gill, heart and muscle, as determined by RT-PCR analyses. In grass carp, the distribution of desaturase transcripts appears to be more confined, being highly detectable in the liver and much less in the brain (Chang et al., 2001). In contrast to its expression in grass carp, expression of stearoyl-CoA desaturase in milkfish was detectable in tissues of the liver, brain, kidney, gill, heart and muscle. These observations suggest that gene-regulation mechanisms for this enzyme are present in a variety of tissues, and that desaturase is regulated through multiple tissue-specific regulatory factors.

In comparison with tissue expression patterns in other teleosts, stearoyl-CoA desaturase transcripts in milkfish are widely distributed. Differences in the expression profile of desaturase among vertebrates imply disparate regulation mechanisms and possibly reflect species-specific differences in the physiological essentiality and requirements of this enzyme in physiological adaptation (Chang et al., 2001).

The stearoyl-CoA desaturase sequence of milkfish is as highly conserved as those of common carp (Tiku et al., 1996) and grass carp (Chang et al., 2001), but these species differ greatly in their cold tolerance and adaptability. This may suggest that milkfish are incapable of expressing stearoylCoA desaturase in sufficient quantities to cope with cold temperature challenge, even though the expression distribution of stearoyl-CoA desaturase in milkfish is much wider than that in grass carp. An alternate possibility is that stearoyl-CoA desaturase is not the only factor involved in the thermal adaptation of fish (Hazel, 1984; Cossins, 1994), and that other factors, such as energy metabolic enzymes and cold shock proteins, might be simultaneously involved in the process of physiological compensation and adaptation (Jones et al., 1996). This remains to be further clarified.

\section{Acknowledgements}

This work was supported by a research grant from the National Science Council, Taiwan, Republic of China to CMK (NSC89-2311-B-002-024B28). We are grateful to Ms Mei-Jane Fang for the DNA sequencing work at Academia Sinica.

\section{References}

Bagarinao, T., 1994. Systematics, distribution, genetics and life history of milkfish, Chanos chanos. Environ. Biol. Fish. 39, 23-41.

Casimir, D.A., Ntambi, J.M., 1996. cAMP activates the expression of stearoyl-CoA desaturase gene 1 during early preadipocyte differentiation. J. Biol. Chem. 271, 29847-29853.

Chang, B.E., Hsieh, S.L., Kuo, C.M., 2001. Molecular cloning of full-length DNA encoding delta-9 desaturase through PCR strategies and its genomic organization and expression in grass carp (Ctenopharyngodon idella). Mol. Reprod. Dev. 58, 245-254.

Chomczynski, P., Sacchi, N., 1989. Single-step method of RNA isolation by acid-guanidiniumthiocyanate-phenol-chlorofrom extraction. Anal. Biochem. 162, 156-159.

Cossins, A.R., Bowler, K., 1987. Rate compensation and capacity adaptation. In: Cossins, A.R. (Ed.), Temperature Biology of Animals. Chapman and Hall Press, New York, pp. 155-203.

Cossins, A.R., 1994. Homeoviscous adaptation of biological membranes and its functional significance. In: Cossins, A.R. (Ed.), Temperature Adaptation of Biological Membranes. Portland Press, London, pp. 63-76.

de Antueno, R.J., Cantrill, R.C., Huang, Y.S., Elliot, M., Horrobin, D.F., 1993. Relationship between mouse liver delta 9 desaturase activity and plasma lipids. Lipids 28, 285-290.

Enoch, H.G., Catala, A., Strittmatter, P., 1976. Studies of the substrate specificity, enzyme-substrate interactions, and the function of the lipid. J. Biol. Chem. 251, 5095-5130.

Felsenstein, J., 1995. PHYLIP (Phylogeny Inference Package) Version 3.57c. Department of Genetics, University of Washington, Seattle. computer program distributed by the author

Györfy, Z., Benkö, S., Kusz, E., Maresca, B., Vígh, L., Duda, E., 1997. Highly increased TNF sensitivity of tumor cells expressing the yeast delta 9-desaturase gene. Biochem. Biophys. Res. Commun. 241, 465-470.

Hazel, J.R., 1984. Effects on temperature on the structure and metabolism of cell membrane in fish. Am. J. Physiol. 246, R460-R470.

Holloway, P.W., 1971. A requirement for three protein components in microsomal coenzyme A desaturation. Biochemistry 10, 1556-1560.

Ideta, R., Seki, T., Adachi, K., 1995. Sequence analysis and characterization of FAR-17c, an androgen-dependent gene in the flank organs of hamsters. J. Dermatol. Sci. 9, 94-102. 
Itoh, R., Toda, K., Takahashi, H., Takano, H., Kuroiwa, T., 1998. Delta-9 fatty acid desaturase gene containing a carboxyl-terminal cytochrome $b 5$ domain from the red alga Cyanidioschyzon merolae. Curr. Genet. 33, $165-170$.

Jeffcoat, R., 1979. The biosynthesis of unsaturated fatty acids and its control in mammalian liver. Essays Biochem. 15, 1-36.

Jeffcoat, R., Brawn, P.R., Safford, R., James, A.T., 1977. Properties of rat liver microsome stearoylcoenzyme A desaturase. Biochem. J. 161, 431-437.

Jones, B.H., Maher, M.A., Banz, W.J. et al., 1996. Adipose tissue stearoyl-CoA desaturase mRNA is increased by obesity and decreased by polyunsaturated fatty acids. Am. J. Physiol. 271, E44-E49.

Kaestner, K.H., Ntambi, J.M., Kelly, T.J., Lane, M.D., 1989. Differentiation-induced gene expression in 3T3-L1 preadipocytes. A second differentially expressed gene encoding stearoyl-CoA desaturase. J. Biol. Chem. 264, 14755-14761.

Kyto, J., Doolittle, R.R., 1982. A simple method for displaying the hydropathic character for protein. J. Mol. Biol. 157, 105-132.

Lee, J.A.C., Cossins, A.R., 1990. Temperature adaptation of biological membranes: differential homeoviscous responses in brush-bored and basolateral membranes of carp intestinal mucosa. Biochem. Biophys. Acta 1026, 195-203.

Legrand, P., Hermier, D., 1992. Hepatic delta 9 desaturation and plasma VLDL level in genetically lean and fat chickens. Int. J. Obes. Relat. Metab. Disord. 16, 289-294.

Los, D.A., Murata, N., 1998. Structure and expression of fatty acid desaturase. Biochim. Biophys. Acta 1394, 3-15.

Luo, C., McSwain, J.L., Tucker, J.S., Sauer, J.R., Essenberg, R.C., 1997. Cloning and sequence of a gene for the homology of the stearoyl-CoA desaturase from salivary glands of the tick Amblyomma americanum. Insect Mol. Biol. 6, 267-271.

Macartney, A.I., Tiku, P.E., Cossins, A.R., 1996. An isothermal induction of $\Delta^{9}$-desaturase in cultured carp hepatocytes. Biochim. Biophys. Acta 1302, 207-216.

Mihara, K., 1990. Structure and regulation of rat liver microsomal stearoyl-CoA desaturase gene. J. Biochem. 108, 1022-1029.

Miller, C.W., Ntambi, J.M., 1996. Peroxisome proliferators induce mouse liver stearoyl-CoA desaturase 1 gene expression. Proc. Natl. Acad. Sci. USA 93, 9443-9448.

Miller, C.W., Waters, K.M., Ntambi, J.M., 1997. Regulation of hepatic stearoyl-CoA desaturase gene 1 by vitamin A. Biochem. Biophys. Res. Commun. 231, 206-210.
Murata, N., Wada, H., 1995. Acyl-lipid desaturases and their importance in the tolerance and acclimation to cold of cyanobacteria. Biochem. J. 308, 1-8.

Nakashima, S., Zhao, Y., Nozawa, Y., 1996. Molecular cloning of delta 9 fatty acid desaturase from the protozoan Tetrahymena thermophila and its mRNA expression during thermal membrane adaptation. Biochem. J. 317, 29-34.

Ntambi, J.M., 1992. Dietary regulation of stearoyl-CoA desaturase 1 gene expression in mouse liver. J. Biol. Chem. 267, 10925-10930.

Ntambi, J.M., Buhrow, S.A., Kaestner, K.H. et al., 1988. Differentiation-induced gene expression in 3T3-L1 preadipocytes. Characterization of a differentially expressed gene encoding stearoyl-CoA desaturase. J. Biol. Chem. 263, 17291-17300.

Panpoom, S., Los, D.A., Murata, N., 1998. Biochenical characterization of a $\Delta-12$ acyl-lipid desaturase after overexpression of the enzyme in Escherichia coli. Biochem. Biophys. Acta 1390, 323-332.

Rogers, M.J., Strittmatter, P., 1973. Lipid-protein interactions in the reconstitution of the microsomal reduced nicotinamide adenine dinucleotide-cytochrome b5 reductase system. J. Biol. Chem. 248, 800-806.

Schünke, M., Wodtke, E., 1983. Cold-induced increase of and desaturase activities in endoplasmic membranes of carp liver. Biochim. Biophys. Acta 734, 70-75.

Shanklin, J., Whittle, E., Fox, B.G., 1994. Eight histidine residues are catalytic essential in a membraneassociated iron enzyme, stearoyl-CoA desaturase, and are conserved in alkane hydroxylase and xylene monooxygenase. Biochemistry 33, 12787-12794.

Sperling, P., Hammer, U., Friedt, W., Heinz, E., 1990. High oleic sunflower: studies on composition and desaturation of acyl groups in different lipids and organs. Z. Naturforsh. 45C, 166-172.

Strittmatter, P., Spatz, L., Corcoran, D., Rogers, M.J., Setlow, B., Redline, R., 1974. Purification and properties of rat liver microsomal stearoyl coenzyme A desaturase. Proc. Natl. Acad. Sci. USA 71, 4565-4569.

Stukey, J.E., McDonough, V.M., Martin, C.E., 1990. The OLE1 gene of Saccharomyces cerevisiae encodes the delta 9 fatty acid desaturase and can be functionally replaced by the rat stearoyl-CoA desaturase gene. J. Biol. Chem. 265, 20144-20149.

Thiede, M.A., Ozols, J., Strittmatter, P., 1986. Construction and sequence of cDNA for rat stearoyl coenzyme A desaturase. J. Biol. Chem. 261, 13230-13235.

Thompson, G.A., Scherer, D.E., Foxall-Van Aken, S. et al., 1991. Primary structures of the precursor and mature forms of stearoyl-acyl carrier protein desat- 
urase from safflower embryos and requirement of ferredoxin for enzyme activity. Proc. Natl. Acad. Sci. USA 88, 2578-2582.

Thompson, J.D., Higgins, D.G., Gibson, T.J., 1994. CLUSTAL W: improving the sensitivity of progressive multiple sequence alignment through sequence weighting, position-specific gap penalties and weight matrix choice. Nucleic Acids Res. 22, 4673-4680.

Tiku, P.E., Gracey, A.Y., Macartney, A.I., Beynon, R.J., Cossins, A.R., 1996. Cold-induced expression of delta 9-desaturase in carp by transcriptional and posttranslational mechanisms. Science 271, 815-818.

Tocher, D.R., Bell, J.G., Sargent, J.R., 1996. Introduction of delta-9 acyl desaturation in rainbow trout (Oncorhynchus mykiss) liver by dietary manipulation. Comp. Biochem. Physiol. 113B, 205-212.

Trueman, R.J., Tiku, P.E., Caddick, M.X., Cossins, A.R.,
2000. Thermal thresholds of lipid restructuring and delta 9-desaturase expression in the liver of carp (Cyprinus carpio L.). J. Exp. Biol. 203, 641-650.

Ward, R.J., Travers, M.T., Richards, S.E. et al., 1998. Stearoyl-CoA desaturase mRNA is transcribed from a single gene in the ovine genome. Biochim. Biophys. Acta 1391, 145-156.

Waters, K.M., Miller, C.W., Ntambi, J.M., 1997. Localization of a polyunsaturated fatty acid response region in stearoyl-CoA desaturase gene 1. Biochim. Biophys. Acta 1349, 33-42.

Zhang, L., Ge, L., Parimoo, S., Stenn, K., Prouty, S.M., 1999. Human stearoyl-CoA desaturase: alternative transcripts generated from a single gene by usage of tandem polyadenylation sites. Biochem. J. 340, $255-264$ 